\title{
The Parental Alienation Syndrome: What Is It and What Data Support It?
}

\author{
Kathleen Coulborn Faller \\ University of Michigan School of Social Work
}

This article describes the parental alienation syndrome, its proposed characteristics and dynamics, and the methods used to document its presence. Research related to various tenets of the parental alienation syndrome is then reviewed. Finally, the syndrome's utility for mental health professionals and courts in explaining allegations of sexual abuse in situations of divorce is evaluated.

C Ahildren may side with one of their parents when parents divorce. More recently, a somewhat different phenomenon, the parental alienation syndrome, has been proposed. The parental alienation syndrome offers an explanation for reports of sexual abuse when parents are divorcing or are divorced. It has received consideration by professionals, some acclaim in the media, and attention in the courtroom. It deserves and requires our critical examination. This article will describe the parental alienation syndrome, specifically its definition, hypothesized characteristics, proposed underlying dynamics, and related evaluation strategies. The article will also discuss research applicable to the parental alienation syndrome and will evaluate its utility in making decisions about sexual abuse.

\section{THE PARENTAL ALIENATION SYNDROME}

The essence of the parental alienation syndrome is a circumstance in which a child demonstrates a strong affinity for one parent and alienation from the other, usually when parents are divorcing or are divorced. In addition, the negative behaviors the child attributes

CHILD MALTREATMENT, Vol. 3, No. 2, May 1998 100-115 (C) 1998 Sage Publications, Inc. to the alienated parent are trivial, highly exaggerated, or totally untrue. In most cases, these behaviors include an allegation of sexual abuse.

Richard A. Gardner is the professional who invented the term, parental alienation syndrome. Gardner has written extensively about the parental alienation syndrome and about companion strategies for assessing allegations of sexual abuse. In his handout Qualifications of Richard A. Gardner, M.D. for Providing Court Testimony, Gardner (1992b) states that as he worked on child custody disputes in divorce in the early 1980s, he began seeing a "new psychiatric disorder," for which he coined the term "Parental Alienation Syndrome." He adds that he wrote his first article on it in 1985 and published his first book about the syndrome, The Parental Alienation Syndrome and the Differentiation Between Fabricated and Genuine Child Sex Abuse, in 1987 (Gardner, 1992b, p. 2).

Important concepts for understanding the parental alienation syndrome are its characteristics, including Gardner's definition of its usual product, a false allegation of sexual abuse; Gardner's view about how this syndrome develops; and his beliefs about other human characteristics not specific to the parental alienation syndrome. These concepts and two procedures that Gardner has developed for evaluating sexual abuse accusations will be discussed in this section.

\section{Elements of the Parental Alienation Syndrome}

According to Gardner, the two moving parties in the parental alienation syndrome are the child and the parent to whom the child is cathected (i.e., concentrating psychic energy, attached), described as "the accusing parent." According to Gardner, acts of the alienated or "accused parent" have little or nothing to do with the child's negative feelings about the parent and allegations against him or her. Specifically, Gardner says the alienated parent has "provided nor- 
mal loving parenting or, at worst, exhibited minimal impairments in parenting capacity" (Gardner, 1992b, pp. xviii; repeated verbatim on p. 61). In fact, he makes a point in his 1992 book that the parental alienation syndrome only applies to false allegations (Gardner, 1992a). If a child is alienated from a parent who has actually maltreated the child, this is not the parental alienation syndrome. It is something else.

Gardner (1992a) regards this "psychiatric disorder" to be on the rise, stating that he finds it in $90 \%$ of the children he sees who are involved in custody litigation (p. 59). He also says that $90 \%$ of the time, the accusing parent is the child's mother, the accused then being the child's father. However, in the remaining cases, these roles are reversed (Gardner, p. 106). ${ }^{1}$

Gardner differentiates the parental alienation syndrome from ordinary programming or brainwashing. He says the phenomenon is initiated by the accusing parent who programs the child, but the child actually adds his or her own material-that is, specific complaints such as an allegation of sexual abuse. In his 1992 book about the syndrome, Gardner (1992a) states that he has identified three different types of this disorder: severe, moderate, and mild parental alienation syndrome.

\section{Characteristics of the Parental Alienation Syndrome}

The major components of the parental alienation syndrome are found in characteristics of the child, the accuser, and the allegation of sexual abuse.

The child. Characteristics found in the child are the following: The child exhibits obsessive hatred of the alienated parent, based on "weak, frivolous, or absurd" complaints (Gardner, 1992a, p. 68). Moreover, these complaints may be characterized by "borrowed scenarios," presumably borrowed from the loved parent (Gardner, 1992a, pp. 77-80). In addition, there is a lack of ambivalence regarding feelings for either the loved or hated parent, an absence of guilt about hating the alienated parent, and reflexive support for the loved parent. Finally, the child also expresses animosity toward other members of the alienated parent's family. For example the child says, "I don't want to see Uncle Ted because he made me feel bad about not seeing my father" (Gardner, pp. 80-81).

The accusing parent. The primary characteristics of the falsely accusing parent or mother are efforts to program or brainwash. Gardner says that motives for these acts range from the entirely conscious to the deeply unconscious.
Conscious strategies include calling the father names, presumably in the child's presence; destroying items in the house that are mementos of him; and tearing up photographs of his relatives. In addition, she may blame him entirely for the marital demise and take no responsibility for her own failings. Gardner (1992a) cites the following as conscious brainwashing strategies: requiring the father "to park in front the house and blow the horn" when he comes to get the child for visits (p. 86), obtaining "restraining orders ... [as a] result of fabricated and even delusional complaints about ... violence" (p. 87), choosing persons other than the father as baby-sitters, and not sending the child for visits when sick. Gardner also describes a variety of maneuvers to interfere with the father's visits and phone contacts with the child as programming. In addition, the mother may begin with "luring" the oldest child into alienation and then progress to younger children (p. 98).

Among unconscious programming maneuvers are the following: If the mother is neutral regarding visits, Gardner (1992b) says she is "communicating criticism of the father," and likewise, if she lets the child decide whether to visit, this is unconscious brainwashing ( $p$. 100). Saying things such as "You have to go see your father. If you don't he'll take us to court" (p. 101) is another example. In addition, Gardner states that the mother calling the child during a visit to query what the child and father have been doing and asking if the child is all right when he or she returns are examples of unconscious brainwashing. Other examples include failing to talk about the father and moving to a distant city. The latter communicates to the child that visits are not important.

The false allegation. In discussing what he means by the term "false allegation of sex abuse," Gardner (1992c) says that subsumed under this rubric are cases in which the allegation is a fabrication as well as cases in which the accuser is delusional. He further states that an accusation may begin as a fabrication but come to be believed by the accuser, in which case, the accuser is then delusional. In fact, he says that false allegations appear along a continuum from complete fabrication to complete delusion.

There does not appear to be any room in Gardner's definition for honest mistakes or misinterpretations of information. Nor does he consider cases that might involve exaggeration or some factual material and some nonfactual material.

\section{Causes of the Parental Alienation Syndrome}

Obviously, an important issue is why the mother and the child behave this way. Gardner describes the psychodynamics and motivation that lead children 
and their mothers to become involved in this alienation and to make false allegations of maltreatment.

The child. Gardner identifies seven psychodynamic factors and one motivational factor that result in children's negative feelings and false allegations. The psychodynamic factors are maintenance of the primary psychological bond, fear of alienating the preferred parent, reaction formation, identification with the aggressor, identification with the idealized person, release of hostility, and sexual rivalry (Gardner, $1992 a, 1992 c)$. The motivational factor is shame over recanting (Gardner, 1992d). Each of these will be discussed briefly.

In speaking of maintenance of the psychological bond, Gardner says that the mother-child bond is stronger than the father-child bond. To assure a continued bond with the mother, the child makes negative statements about the father including, and perhaps most important, that the father has sexually abused the child. The child sees that the mother is pleased by negative statements about her ex-spouse and so makes progressively more serious ones.

Apparently closely related is the second factor, fear of alienating the preferred parent. The accused parent has already deserted the child because he has left the home during divorce. To prevent the remaining parent from deserting him or her, the child will take a position supporting the preferred parent. The child joins the mother "in her campaign of vengeance and vilification of the father" (Gardner, 1992c, p. 128).

The third psychodynamic factor Gardner (1992c) cites is reaction formation. His argument is that the hatred of the father is in fact "a thin disguise for deep love" (p. 128). Furthermore, he asserts that the child's description of unpleasant sexual activities with the father is a reaction formation to cope with wishes for sexual activity with the father. It is the child's way of saying, "It is not I who want him to rape me, it is he who wants to rape me." This assuages the child's guilt about desire for sex with the father (Gardner, 1992c, p. 129).

The fourth factor is another defense mechanism, identification with the aggressor. The aggressor is the mother who is attacking the father. The child is getting "on the bandwagon of the stronger party" (Gardner, 1992c, p. 129). Gardner does not see the father as an aggressor, nor as the stronger of the two parents.

The fifth factor is described by Gardner (1992c) as closely related to the fourth. It is identification with the idealized person. As the mother "denigrates the father, she is likely to whitewash herself" (p. 130). Gardner says that a psychological fusion between mother and child forms, which contributes to the formation of folie $\grave{a}$ deux. Thus, the child and the mother are both delusional with regard to the father's negative traits and behaviors.

Not only may these delusions encompass mother and child but others may also become incorporated. For example, if there is more than one child, the delusion becomes folie à trois or quatre. Gardner (1992b) is also "convinced that . . . a widespread phenomenon" is the mother's or child's psychotherapist joining the delusion. He states, "Parental Alienation Syndrome mothers have a way of finding therapists, almost invariably women, who reflexively join them in their campaign of denigration of the father ... [who] in some cases even join the mother's paranoid delusional system." Furthermore, he states, "Some of these therapists are paranoid themselves. Others harbor deep-seated hostility toward men, hostility so strong that they will seize upon every opportunity to vent their rage on them" (p. 147).

Sixth, Gardner sees the etiology of parental alienation syndrome as deriving from the release of hostility. His argument is that the child is angry for reasons other than any harmful paternal behavior. These include abandonment by the father, financial hardship consequent of the marital demise, lack of attention from parents who are consumed with their divorce, the presence of new partners, and the fact that parents are not reconciling. Anger from these diverse sources is focused on the father and leads to false accusations against him.

The final psychodynamic factor cited by Gardner is sexual rivalry. This seems only to be a factor for daughters. Gardner (1992c) says that the daughter "has a seductive and romanticized relationship with her father" (p. 131). When the father develops a relationship with a new woman, the daughter says, "You've got to choose between her and me," thereby sabotaging the father's relationship with his new partner (Gardner, 1992c, p. 131). Mothers are said sometimes to encourage their daughters in these manipulations because "it serves well their desire for vengeance" (Gardner, 1992c, p. 131).

In addition, Gardner (1992c) states that children may experience shame over recanting, which in fact prevents them from recanting. He enumerates several sources of motivation to retract the allegation of sexual abuse, but "the prospect of being called a liar by the horde of individuals who have jumped on the child's bandwagon is terrible to behold" (p. 132). Thus, the child does not recant despite concern over the consequences of the false allegation to the accused parent.

The accuser. Gardner (1992a) says that mothers feel compelled to alienate their children from the fathers during divorce because they are presently at a disad- 
vantage in obtaining custody. He says this is so because custody decisions are now made based on the "best interests of the child presumption" rather than on the "tender years presumption" (pp. 52-54). He describes the tender years presumption as the presumption that children will be better cared for by their mothers, especially when they are younger. He states this is no longer social policy.

A review of child custody statutes and the actual data about which parent obtains custody raises questions about this hypothesis. Best interests criteria in child custody statutes consist of a range of factors, including some on which mothers are likely to perform better. Even though it is more common than in the recent past for fathers to seek custody or joint custody, in approximately $85 \%$ of the cases, it is still the mother who receives custody (Bogolub, 1997).

In any case, Gardner (1992c) theorizes that mothers are threatened by the prospect that their husbands may gain custody and so engage in "a whole series of exclusionary maneuvers." When these "have not proven successful," they then use the "ultimate weapon" and make allegations of sexual abuse (p. 193). Thus, according to Gardner, the sexual abuse charge is made later rather than earlier in situations of the parental alienation syndrome.

Gardner (1992a) indicates that the mother's expressed concerns about the father's behavior are based on the following underlying factors: desire to maintain the primary psychological bond, fury of the scorned woman, economic disparity, reaction formation, and projection. He also postulates that her exclusionary maneuvers may precede the marital breakup and observes that there is a relationship between maternal overprotectiveness and the parental alienation syndrome. The roles of these factors require further explanation.

Maintenance of the primary psychological bond derives from the "proverbial 'maternal instinct." " When a custody dispute threatens this bond, the mother resorts to a program of "vilification" of the father (Gardner, 1992a, p. 121).

The dynamic that Gardner (1992a) calls the fury of the scorned woman is explained as follows. The mother cannot retaliate directly against the father for divorcing her because he is not there. She does so indirectly by attempting to deprive him of "his most treasured possessions, the children" (p. 122).

The role of economic disparity refers to the resentment the mother feels because not only does her economic position deteriorate with the divorce, but it does more so than the father's. In addition, because she cannot afford high-powered, expensive lawyers, as he can, she must resort to programming the child to hate the father to assure custody (Gardner, 1992a, p. 122).

Gardner (1992a) explains the function of reaction formation in two ways. Like its role with children, hatred is a disguise for love of the ex-spouse. However, reaction formation also operates in relationship to the children. Mothers' "obsessive love of their children is often a cover-up for their underlying hostility" (p. 124)

Projection is often manifested in the allegation of sexual abuse that Gardner (1992a) describes as "the common addition to the Parental Alienation Syndrome." He goes on to state that "many of these allegations are conscious and deliberate." However, in other allegations,

the mother's own suppressed and repressed sexual fantasies are projected onto the child and the father. By visualizing the father having a sexual experience with the child, the mother is satisfying vicariously her own desires to be a recipient of such overtures and activities. (p. 126)

Furthermore, Gardner (1992a) asserts that in some cases, the mother's exclusionary maneuvers predate the divorce, sometimes as early as the birth of the child. For example, the mother restricts the father's role in child care. Her behavior may arise because she is engaged in competition with him for a relationship with the child or to enhance her self-esteem. Alternatively, she may see the father as a danger to the child because of her "own unconscious desires to inflict harm on the baby" (p. 128).

Gardner (1992a) elaborates this theme further under the heading of overprotectiveness. He asserts that there is considerable overlap between maternal overprotectiveness and the development of the parental alienation syndrome. The "overprotective mother is a high risk candidate for providing the kind of programming that may result in a Parental Alienation Syndrome" (p. 131).

Finally, the mother's campaign against the child's father may expand to include attempts to ruin him and/or his reputation and to have him criminally prosecuted. Moreover, in addition to making her own false assertions about his abusive behavior, she "programs" the children to lie about him as well (Gardner, 1992a, p. 193).

\section{Assumptions Underlying the Parental Alienation Syndrome}

Gardner (1991) states that he believes that "perhaps $95 \%$ or more" of all allegations of child sexual abuse are true (p. 7). Furthermore, he is of the opinion that "sexual abuse allegations that arise in the 
intrafamilial situation have a high likelihood of being valid. Incest is probably quite common, especially father [or stepfather]-daughter [or stepdaughter] relations" (p 3). Nevertheless, he says that he is convinced that "the vast majority of allegations in this category [divorce cases with custody disputes] are false" (p. 4).

Gardner never states directly why he is so convinced. Nor, apparently, does he see a contradiction between his position on incest in intact families and incest in divorced or divorcing families. He evidently does not consider that a likely outcome of the discovery of incest is a decision by the mother to divorce the offending father.

Although Gardner gives his opinion that allegations of sexual abuse in divorce are untrue and explains how he believes these false accusations come about, the reader may still have questions. The reader may be wondering how a child who has not been sexually victimized could generate a detailed account of sexual abuse. In addition, Gardner's explanations may leave many readers bewildered as to why a child would do such an unspeakable thing to a parent. Finally, some readers may harbor skepticism that so many mothers could be so disturbed and vindictive and so insensitive to the needs of their children.

Understanding Gardner's perspectives on sexuality and human nature more generally may assist the reader in understanding why he holds the views he does. Again, the focus is on children and adults making accusations of sexual abuse; the focus is not on the accused.

The child. Gardner makes a number of assertions about children in general that he sees as explaining children's false allegations of sexual abuse. These characteristics are not specific to children exhibiting the parental alienation syndrome.

First, children are "polymorphous perverse" (Gardner, 1991, pp. 9-13; repeated verbatim in Gardner, 1992c, pp. 121-125). He states that "children normally exhibit just about any kind of sexual behavior imaginable: heterosexual, homosexual, bisexual, and autosexual." In his opinion, "the normal child experiences and exhibits a wide variety of sexual fantasies and behaviors" (Gardner, 1991, p. 12; Gardner, 1992c, p. 124). To again quote Gardner (1992c), "A four year-old girl, for example, may harbor, among her collection of polymorphous perverse fantasies, thoughts of some kinds of sexual encounters with her father" (p. 125). Therefore, in explaining how children make false allegations, Gardner considers sexualized behavior and statements indicating advanced sexual knowledge, which are regarded as markers of possible sexual abuse by most profession- als writing about this issue (see Faller, 1994; Friedrich, 1990), as characteristics of normal and therefore nonabused children. ${ }^{2}$

Gardner (1992c) adds that when children are caught in sexualized behavior that is internally generated by their own wishes and knowledge, they may blame others. "Daddy made me do it" (p. 126). Moreover, if their initial response of blaming a sibling does not yield the desired attention and support, they may then implicate an adult (p. 126).

Nevertheless, Gardner (1991) does not believe children's sexuality is entirely self-generated. It may also come from exposure to sexual abuse prevention programs, books, and tapes. These teach children about good and bad touches. Exposure to these concepts leads to fantasies about such touching. Thus, sexual abuse prevention material may generate a false allegation of sexual abuse.

Gardner (1991) also sees the exposure to sexuality that saturates the media as playing a role. He cites "profanity" and "vulgarisms" found on MTV, in Rrated movies, and in rock music (p. 19). Although knowledge of profanity is not the same thing as sexual knowledge, X-rated movies and pornographic home videos that he also cites, do contain sexual acts (p. 20).

Besides being polymorphous perverse and being influenced by sexual material, children are also "wicked," according to Gardner. For example, he writes, "What is striking is the degree of sadism that many of these children may exhibit. In many of these cases I have been impressed by what I consider to be the innate cruelty of these children" (Gardner, 1992c, pp. 119-120). He is referring to children who say that they have been sexually abused.

The accusers. Not only does Gardner (1991) think children are polymorphous perverse, but so are adults (p. 25). He believes that "all of us have some pedophilia within us" (p. 26).

Each time the accusers make an accusation, they are likely to be forming an internal visual image of the sexual encounter. With each mental replay, the accusers gratify the desire to be engaging in the activities that the perpetrators are involved in in the visual imagery. (p. 25)

Moreover, some people are more afflicted with pedophilia than others and therefore need to indulge in more frequent imagining of sexual acts with children. Such people are more likely to "produce false sex abuse charges" (Gardner, 1991, p. 26). These dynamics apply not only to mothers making charges of sexual abuse against their ex-spouses but to other people as well. For example, this is what causes parents to express a belief their children have been 
sexually abused in day care. Gardner (1991) states that "the vast majority of allegations" in day care are false, but that "child sex abuse is a common phenomenon in boarding schools, orphanages, and other settings where children live together with adults" (p. 4). Like his views about different manifestations of fatherchild incest, there is a degree of contradiction here that Gardner does not seem to recognize.

The problem of false allegations motivated by arousal to children and vicarious gratification is not limited to parents. Gardner believes that these dynamics also operate among professionals who are involved in the investigation, treatment, and litigation of sexual abuse cases, whom he calls "validators," which is for him a pejorative term. In addition to satisfying their sexual needs by making false allegations of sexual abuse, they are also motivated by greed. They make money by substantiating and treating sexual abuse cases. $^{3}$ According to Gardner (1991, 1992c), these people are poorly educated and poorly trained. Their incompetence and use of flawed techniques lead hundreds of children to falsely claim or affirm sexual victimization.

\section{Strategies for Assessing for the Presence of the Parental Alienation Syndrome}

Although not the primary focus of this article, two methodologies proposed by Gardner for evaluating allegations of sexual abuse that are usually employed to substantiate the existence of parental alienation syndrome will be briefly discussed.

The Sexual Abuse Legitimacy Scale (SALS). The SALS has been used by Gardner and others who accept his ideas, in conjunction with the parental alienation syndrome. In fact, the presence of a custody dispute and the presence of the parental alienation syndrome are two factors in the SALS that indicate high likelihood that the allegation of sexual abuse is false, according to Gardner (1992c).

Although Gardner (1992c) states that the SALS is broadly applicable, the fact that the 84 factors included in it relate to the child, the mother (accuser), and the father (accused of sexual abuse) indicates its primary focus is on father-child incest. Moreover, factors related to the mother, such as "the utilization of exclusionary maneuvers" (p. 191), "direct programming of the child in the sex-abuse realm" (p. 193), "enlistment of the services of a 'hired gun' attorney or mental health professional" (p. 196), a "history of attempts to destroy, humiliate, or wreak vengeance on the accused" (p. 199), and "paranoia," are an integral part of Gardner's description of the parental alienation syndrome. Further examination of the 84 factors in the SALS indicates that its primary function is to diagnose the parental alienation syndrome.

When the SALS was first published by Gardner, factors were differentiated into (a) very valuable differentiating criteria, (b) moderately valuable differentiating criteria, and (c) differentiating criteria of low but potentially higher value. The SALS was published as a separate instrument and had numerical values attached to each factor. A higher score increased the likelihood of sexual abuse. Gardner urged users to be conservative about endorsing items indicative of sexual abuse and said that a score of $50 \%$ of the maximum was "strongly suggestive of sexual abuse." A score of $10 \%$ of the maximum meant that the allegation was false (Gardner, 1987, 1989).

Because the SALS had not been validated and, in fact, had not been the subject of any research; because it was based on Gardner's assumptions about divorce allegations; and because its language lacked neutrality, it was the subject of considerable criticism (e.g., Berliner \& Conte, 1993; Faller, Olafson, \& Corwin, 1993). Eventually, Gardner (1992c) repudiated the numbers but not the factors (pp. xxxiv-xxxv). The SALS as a separate publication no longer is listed in the catalogue for Creative Therapeutics, Gardner's press. Its latest iteration, which appears in True and False Accusations of Child Sex Abuse (1992c) is not a numerical scale. Rather, it is a list of 84 factors, 30 related to the child, 30 related to the mother, and 24 related to the father. ${ }^{4}$

Protocols for Sex-Abuse Evaluation. Gardner's 1995 book, titled Protocols for Sex-Abuse Evaluation, is an expansion of the SALS, although the term Sexual Abuse Legitimacy Scale does not appear in the book. The 1995 book includes six protocols. Thus, to the protocols of the alleged child victim, the accused male (usually the father), and the accusing parent (usually the mother) in intrafamilial cases, it adds three new protocols: the accused female, the accusing parent (usually the mother) in extrafamilal cases, and the adult female victim/belated accuser (also know as an adult survivor of sexual abuse).

Gardner's (1995) book also represents a shift from attributing false allegations to the polymorphous perversity of the child and others to blaming (a) hysteria about sexual abuse (pp. 26-28; repeated verbatim on pp. 332-336) and (b) "interrogations and 'therapy' " (p. 29). Problematic interrogations and "therapy" result in "legal process/ 'therapy' trauma." This trauma is instigated by "one or more of the following: the police, detectives, prosecutors, social workers, 'validators', child advocates, psychiatrists, psychologists, social workers [sic], 'therapists' (often self styled and unlicensed), lawyers, guardians-ad-litem [sic], judges, 
and unfortunately parents" (p. 29). Gardner has developed a series of rather complex timelines that are to be used in differentiating whether the child's symptoms derive from abuse or from "legal process`'therapy.' " These are shown to the child so that the child can designate when his or her symptoms began.

Despite the substitution of the term Protocols for Sex-Abuse Evaluation for the SALS, the expansion of the number of actors involved, and the modest shift of blame, virtually all SALS factors are included in the Protocols, and the parental alienation syndrome figures prominently in the Protocols as a signal that the allegation of sexual abuse is false (Gardner, 1995, pp. 316-317). Of the 30 factors related to the accusing mother in the SALS, 28 are found in 32 factors related to the accusing mother in intrafamilial cases in the Protocols (Gardner, 1995, pp. 265-328). Similarly, all of the 24 "indicators of pedophilia in the male" (accused father) are included in the same order and verbatim in the chapter "Evaluation of the Accused Male" in Gardner's 1995 book. Two are added, "utilization of seductivity [sic]" and "numerous victims" (Gardner, 1995, pp. 193-233). Finally, 29 of the 30 factors related to the alleged child victim appear in the Protocols, but there are an additional 33 factors, making a total of 62 . The added factors are largely techniques for child interviewing, such as the use of doll play and picture drawing, and symptoms of trauma, such as dissociation and preoccupation with the trauma (Gardner, 1995, pp. 56-157).

Gardner (1995) provides questions for assessing each of these factors and guidance about the significance of the findings regarding the truth or falsity of the allegation. Each factor is scored T (true), $F$ (false), or $\mathrm{E}$ (equivocal if the evaluator cannot make a determination).

\section{RESEARCH FINDINGS}

Gardner does not provide any research findings to substantiate his assertions about the proposed characteristics and dynamics of the parental alienation syndrome. When Gardner gives percentages, such as $90 \%$ of false accusers are women, and makes statements, such as the vast majority of allegations of sexual abuse in divorce are false, he does not provide statistics or references to professional literature to support these claims. Rather, he states that he is convinced that a particular finding is a widespread phenomenon. He makes this assertion, for example, regarding his belief that female therapists, who are either man haters or paranoids, partake of folie à trois with mothers and contribute to their campaigns of vilification and vengeance against fathers (Gardner, 1992a, p. 147).
It is important to appreciate a consequence of the fact that Gardner publishes the vast majority of his work himself. His own press, Creative Therapeutics, only publishes his material and no works of other writers. The present selections consist of approximately 100 of his lectures, books, manuals, games, videos, and audiotapes (Gardner, 1996). This means that his work does not have to meet the standards of peer review. Thus, his ideas are not critically evaluated by others knowledgeable in the field before they appear in print.

Furthermore, Gardner appears to have a low regard for the research in this field. In Sex Abuse Hysteria: The Salem Witch Trials Revisited (1991), he states, "The term scientific proof is not applicable to most of the issues discussed here." He goes on to refer to the standard and accepted practice of citing support for professional opinions in existing literature as "specious buttressing" (p. 2).

Nevertheless, there is a body of research that is relevant to some of Gardner's theories. Research findings relevant to the issue of false allegations of sexual abuse in divorce, polymorphous perversity of children, the role of prevention programs and sexual stimuli in the environment, and polymorphous perversity of adults will be covered in the next section.

\section{Research Findings Relevant to the Parental Alienation Syndrome}

There is a body of literature on false allegations of sexual abuse in divorce (see Faller et al., 1993, for a critical review of these studies). It is surprising that none of this work is referenced in Gardner's (1992a) book, The Parental Alienation Syndrome, although most of the studies predate the publication of the book. In fact, this book of almost 350 pages has only 60 references, 18 of which are to Gardner's writings. Gardner published his first book on the parental alienation syndrome in 1987 and seems to have incorporated or considered little of the work done since then in his 1992 book on this topic. It contains only four references later than 1987, aside from his own works: One is a newspaper article, the second a personal communication, the third a definition from a dictionary, and the fourth an article published in Accusations of Child Abuse, a nonjuried journal published by Ralph Underwager. His 1995 book is better referenced but ignores a large body of recent research on children's memory and suggestibility, on repressed memories, and on child sexual abuse more generally.

The research on false allegations of sexual abuse in divorce contains findings related to the following of Gardner's assertions: that $90 \%$ of disputed custody cases exhibit the parental alienation syndrome, that 
the vast majority of allegations in divorce are false, that $90 \%$ of allegations are made by mothers, and that these allegations are vindictively made (Faller et al., 1993).

In reviewing this research, it is important to attend to the following issues: (a) sample size, (b) sample bias, and (c) how a false allegation is determined (Faller et al., 1993). Many studies involve few cases and/or come from the practices of those who report on them, which introduces biases: Benedek and Schetky (1985) -18 cases, Green (1986) -11 cases, Kaplan and Kaplan (1981) - 1 case, and Schuman (1986) - 7 cases. Also, definitions of false allegations in these studies derive from opinions of the clinicians conducting them. Because of these limitations, these studies should be given less weight than those with larger numbers, less bias, and consensual definitions of true and false allegations.

The parental alienation syndrome (and accompanying allegations of abuse) are very common in custody disputes. Gardner (1992a) says that "the frequency of false accusations [of sexual abuse] is quite high" when the parental alienation syndrome is present (p. 126). As already noted, he finds the parental alienation syndrome in $90 \%$ of custody disputes.

Thoennes and Tjaden (1990) and Thoennes, Pearson, and Tjaden (1988) examined 9,000 cases from domestic relations courts involving custody or visitation disputes. These cases came from 12 jurisdictions in the United States. Of these 9,000 cases, $1.9 \%$ (169 cases) involved allegations of sexual abuse. Obviously, this is a more representative sample of disputed custody cases than those Gardner sees in his private practice. Although this research does not speak directly to the presence of the parental alienation syndrome, the very small number of custody disputes involving sexual abuse allegations (half of which were deemed likely) certainly undermines Gardner's (1991) claim of the widespread presence of false allegations of sexual abuse as part of the parental alienation syndrome.

The vast majority of allegations of sexual abuse in contested divorce are false. None of the research supports Gardner's (1991, 1992c) opinion that the vast majority of allegations in divorce are false. The study that comes the closest is that of Benedek and Schetky (1985), which contained 18 cases, 10 of which they thought were false. However, not only is the sample rather small but 4 of the cases did not involve custody disputes related to divorce. In addition, Benedek has stated that because she often serves as an expert witness for the accused in these cases and does not wish to support actual offenders, she reviews case materials before agreeing to be the expert and refuses the case if she believes the allegation is true (see Morgan v. Foretich, Foretich, E Foretich, 1987). This practice screens out true allegations of sexual abuse. Therefore, results from this study cannot be representative of actual proportions of true and false allegations in divorce. Other studies find a false allegation rate of about one third or less (Faller, 1991; Faller \& DeVoe, 1995; Green, 1986; Jones \& Seig, 1988; Paradise, Rostain, \& Nathanson, 1988; Thoennes \& Tjaden, 1990).

Two studies with large samples, the Thoennes and Tjaden (1990) study and that of Faller and DeVoe (1995), illustrate the impact of definition of false allegations on findings. Using as a measure of the veracity of the allegation the disposition of child protective services and/or the opinion of a court appointed evaluator, Thoennes and Tjaden (1990) found one third of cases unlikely, half likely, and the remainder uncertain.

Faller and DeVoe (1995) examined 215 allegations of sexual abuse seen at a university-based multidisciplinary clinic. The determination of this team of experts was used to decide the likelihood of the allegation. A higher percentage was deemed likely, $72.6 \%$, with $20 \%$ considered unlikely and $7.4 \%$ uncertain. These proportions are similar to those of Jones and Seig (1988), who had a smaller sample, 20 cases, but who used a similar multidisciplinary procedure for decision making. They found $70 \%$ likely, $20 \%$ unlikely, and $10 \%$ uncertain.

Arguably, multidisciplinary teams have the opportunity to assess accusations of sexual abuse in greater depth than do child protection workers, who have high caseloads, or court-appointed experts, who may be looking at a range of issues. In addition, multidisciplinary teams have the advantage of "two or more heads, which are better than one," and of greater expertise than either child protective services workers, with their high rate of turnover, and court experts, whose skills may be in custody/visitation decisions rather than in sexual abuse. Therefore, the higher rate of likely cases found by Faller and DeVoe (1995) and by Jones and Seig (1988) may be more accurate than the rate found by Thoennes and Tjaden (1990), whose sample was more representative. If this is so, then Gardner's (1991) assertions that the vast majority of these accusations are false are even less congruent with research findings.

Of the false allegations in divorces, $90 \%$ are made by mothers against fathers. Most studies examine who is accused rather than who makes the accusation. They also look at cases deemed true as well as those deemed false. One study that did look at accuser role is that of 
Benedek and Schetky (1985). They report that 9 of the 10 cases they considered false were made by mothers. However, as already noted, their sample was small, so generalizations cannot be made from it. Thoennes and Tjaden (1990) found that $67 \%$ of the 169 allegations in their study were made by mothers and $28 \%$ by fathers. Less than half of cases were allegations by mothers against fathers. When the researchers looked at the proportion of reports by mothers judged unlikely, it was $33 \%$, the same percentage as that for the sample as a whole (Thoennes et al., 1988, p. 7 of tables).

Of course, the gender of complainants and alleged offenders needs to be interpreted in light of current knowledge of offender gender. The vast majority of sexual abusers are male.

Mothers consciously fabricate false allegations or are delusional. Although researchers may conclude that an accusation of sexual abuse is not true, very few have looked at the etiology of false allegations. Benedek and Schetky (1985) gave psychiatric diagnoses, usually paranoia, to the adults whom they decided had made false accusations. They also made observations about the motivation of the accuser. They report the following three motivations: a desire to get their exspouses out of their lives, vindictiveness, and "crying wolf." However, these two different etiologies are not integrated in the article, and the series of motivations seem more impressionistic than scientific.

Thoennes and Tjaden (1990) examined the narratives in their cases to see if the professionals forming the opinions offered an explanation for their etiologies. There was relevant information in 58 of 169 cases. They found 8 cases in which the false allegation appeared to be maliciously made and 5 cases in which the accuser's psychological problems caused the accusation. They do not indicate who made these reports. In Faller and DeVoe's (1995) sample of 215 cases, 10 appeared to be calculated false allegations. Of these, 6 were made by men. However, one male made 4 of them.

Again, research findings from large samples with defined methodology do not support Gardner's assertion that large numbers of mothers (or others) involved in divorce make false allegations either by design or because they are mentally ill.

\section{Research Findings Relevant to the Polymorphous Perversity of Children.}

Gardner (1992c) bases his assertions that children are polymorphous perverse and are capable of generating sexual fantasies without sexual experience on Freud's theory of infantile sexuality. He says that he agrees with Freud that children have fantasies but does not think the fantasies only involve sexual intercourse. Especially when young children have them, these wishes may involve the touching of various parts of the body with other parts (p. 125). Gardner's assertions about the polymorphous perversity of children will be considered from three perspectives: the evolution of and current views about Freud's theory of infantile sexuality, the research on children's sexualized behavior, and the criteria used to substantiate sexual abuse.

Freud's theory of infantile sexuality. A consideration of the evolution of Freud's theory and current views about it are instructive in determining the validity of this explanation of sexualized behavior and sexual knowledge. As Freud was psychoanalyzing young women with hysteria, he found that they related childhood histories of sexual victimization. He concluded that the etiology of hysteria was a childhood experience of sexual abuse. He was severely criticized by his colleagues and eventually altered his theory. It is not clear the extent to which his inability to believe that incest could be so widespread and/or that concerns about incest in his own family led to this change of heart (Masson, 1987). Nevertheless, he recanted his earlier belief in the pivotal role of sexual victimization. $\mathrm{He}$ decided it was not actual incest but incestuous fantasies or wishes that were being reported by his female patients. Thus, what Freud initially viewed as a phenomenon derived from adults' behaviors became a consequence of children's thoughts.

Recent advances in knowledge about the prevalence of sexual abuse and its impact have led professionals to reconsider Freud's theories. It is estimated that 1 in 3 or 4 women and 1 in 6 to 10 men are sexually abused during childhood (Faller, 1990). A more widely held view than that propounded by Gardner is that Freud was right in the first instance and wrong in his revisions (e.g., Faller, 1988a; Herman, 1979; Masson, 1987; Miller, 1984; Rush, 1977; Ward, 1985).

Research on children's sexual knowledge and sexualized behavior. In many of his writings (e.g., his 1991 and 1992 books), Gardner indicates that sexual statements and behaviors in children are not indexes of sexual victimization. For example, he says, "Each child is likely to have a 'favorite' list of sexual activities that provide interest and pleasure" (Gardner, 1991, p. 12). $\mathrm{He}$ further asserts that persons who consider statements indicating sexual thoughts or knowledge and sexualized behavior as " 'proof' that children have been sexually abused have caused many truly innocent individuals an enormous amount of harm, even to the point of long prison sentences" (Gardner, 1991, 
p. 13). In his 1995 book, Gardner's position has shifted somewhat. He says that in false allegations, the child incorporates fantasy of sexual activities that are ludicrous or pointless (for the offender), citing as illustrative a child alleging that the offender put his penis in his or her mouth and did not move it as having the hallmarks of a false allegation (p. 61). ${ }^{5}$

An opinion that advanced sexual knowledge and explicit sexual behavior can be self-generated is not supported by research findings. Not all sexually abused children exhibit sexualized behavior nor manifest advanced sexual knowledge. In addition, children may learn about sex from sources other than sexual victimization, a finding that will be discussed below. Nevertheless, sexualized behavior is the marker most likely to distinguish sexually abused from nonabused children (Friedrich, 1994). For example, Waterman and Lusk (1993) report on 11 studies using the Achenbach Child Behavior Checklist (CBCL) to compare children disclosing sexual abuse and children without such a history. Sexually abused children had significantly higher scores on the Sexual Problems subscale of the CBCL than did nonabused children.

Friedrich, from the Mayo Clinic, is the researcher who has explored the issue of sexualized behavior in the greatest depth. Over a period of years, he has developed a standardized measure, the Child Sexual Behavior Inventory (CSBI), that reliably differentiates children, ages 2 to 12 , with a history of sexual abuse from children without a sexual abuse history (Friedrich, 1990, 1993, 1994). Friedrich and colleagues have conducted a number of studies comparing CSBI results for children with a history of sexual abuse and those without, using children from several sites in the United States. The instrument continues to be refined (Friedrich et. al, 1996a, 1996b).

Illustrative of findings regarding the low rates of sexualized behavior by children without a history of sexual abuse are the following data: Less than $1 \%$ of the children were reported by their caretakers to put their mouths on another's sex parts, and the rate is zero for children ages 7 to 12 . Similarly, less than $1 \%$ of nonabused children asked others to engage in sex acts (Friedrich, Grambsch, Broughton, Kuiper, \& Beilke, 1991; Friedrich et al., 1996b). In contrast, a substantial minority of children with a history of sexual abuse engage in these behaviors.

Studies using anatomical dolls (which Gardner disapproves of; see Gardner, 1995, p. 158) also support the importance of sexualized behavior as a differentiating characteristic of sexually abused children. These studies are of two types: those that ascertain the reaction of nonabused children to anatomical dolls (Boat
\& Everson, 1994; Everson \& Boat, 1990; Sivan, Schor, Koeppl, \& Nobel, 1988) and those that compare the responses to the dolls of children with a sexual abuse history to those without such a history (August \& Foreman, 1989; Cohen, 1991; Jampole \& Webber, 1987; White, Strom, Santilli, \& Halpin, 1986). Studies of nonabused children generally indicate that anatomical dolls do not elicit explicit sexual behavior from sexually naive children but, as will be discussed below, serve as a stimulus for sexually knowledgeable children. Comparative studies of reportedly abused and not abused children generally show that sexually abused children are significantly more likely than nonabused children to demonstrate explicit sexual behavior with anatomical dolls. However, not all abused children do this, and in some studies, a small number of children without a diagnosis of sexual abuse showed sexual behavior with the dolls (Cohen, 1991; Jampole \& Webber, 1987).

Criteria for substantiating sexual abuse. A number of researchers and clinicians working in the field of sexual abuse have developed or have studied strategies for deciding whether a child has been sexually abused. Some of this work is data based (Conte, Sorenson, Fogarty, \& Dalla Rosa, 1991; Faller, 1988b; Jones \& McGraw, 1987; Raskin \& Esplin, 1991). Faller (1994) reviewed 11 of these works, noting the commonalties and differences among the criteria different writers present for decision making. Of relevance here is that all of the 11 include the child's description of sexual abuse as a positive indicator of sexual abuse (Benedek \& Schetky, 1987; Conte et al., 1991; Corwin, 1988; De Young, 1986; Faller, 1988b; Heiman, 1992; Jones \& McGraw, 1987; Klajner-Diamond, Wehrspann, \& Steinhauser, 1987; Raskin \& Esplin, 1991; Sgroi, 1982; Sink, 1988). In addition, 8 include detail about the sexual abuse (De Young, 1986; Faller, 1988b; Heiman, 1992; Jones \& McGraw, 1987; KlajnerDiamond, Wehrspann, \& Steinhauer, 1987; Raskin \& Esplin, 1991; Sgroi, 1982; Sink, 1988); 8 include advanced sexual knowledge (Benedek \& Schetky, 1987; Conte et al., 1991; Corwin, 1988; Faller, 1988b; Heiman, 1992; Jones \& McGraw, 1987; Raskin \& Esplin, 1991; Sgroi, 1982); and 5 include sexualized behavior, as reported by others (Conte et al., 1991; Corwin, 1988; Heiman, 1992; Jones \& McGraw, 1987; KlajnerDiamond et al., 1987; Sgroi, 1982), as markers of sexual victimization.

Therefore, it appears that experts in sexual abuse disagree with Gardner's (1991) assertion that sexual statements and sexualized behavior are characteristic of nonabused children and can be spontaneously generated by sexual fantasies. 


\section{Research Findings Related to False Allegations, Prevention Programs, and "the ubiquity of environmental sexual stimuli" \\ (Gardner, 1991, pp. 19-20)}

As noted earlier, Gardner believes that sexual abuse prevention programs and sexual material in the media can result in false allegations of sexual abuse. As with other assertions, he presents no data. Rather, Gardner conjectures that the impact of prevention programs is that they will generate fantasies of touching private parts and, subsequently, accusations by the programs' recipients that adults are doing this to them. Others who have raised concerns about prevention programs have viewed the risk somewhat differently. They worry that children will assume all touching of the genitals is "bad touching" and will mistakenly assume such contact that occurs as part of child care or medical care is sexual abuse. To guard against this, many sexual abuse prevention programs point out these exceptions.

To date, evaluations of sexual abuse prevention programs do not indicate that they are the source of false allegations of sexual abuse (Kolko, 1988; Wurtele \& Miller-Perrin, 1992). However, such programs may generate disclosures of what are determined to be actual cases of sexual abuse (Hazzard, Webb, Kleemeier, Angert, \& Pohl, 1991; Plummer, 1986; Wurtele \& Miller-Perrin, 1992).

Gardner is right that there is more sexual material in the media than there was in the past; there are also more types of media (e.g., television and videotapes). Indeed, children can learn about sex from these sources, as well as from observation of sex acts, communication with peers, and sex-education programs. That some children without a history of sexual abuse demonstrate sexualized behavior with anatomical dolls is a case in point. In an anatomical doll study of 223 2- to 5-year-olds without a history of sexual abuse, Boat and Everson introduced the dolls, disrobed them, and asked the children to "show me what the dolls do together." Of these children, $6 \%$ demonstrated intercourse behavior using the dolls. None of the 2-year-olds did, but approximately a fourth of older males of lower socioeconomic status did. When the researchers followed up on the sexually knowledgeable children, they ascertained that they had been exposed to sex but not abused (Boat \& Everson, 1994; Everson \& Boat, 1990).

In addition, research indicates that children ages 2 to 12 are curious about private body parts and persons of the opposite sex. For example, Friedrich et al. (1991) found that $23 \%$ of children without a history of sexual abuse were interested in the opposite sex,
$28 \%$ of them tried to observe people undressing, and almost $31 \%$ touched breasts. Similarly, Rosenfeld and colleagues found that $55 \%$ of boys up to age 10 and $70 \%$ of girls had touched the private parts of the parent of the opposite sex at least once (Rosenfeld, Bailey, Siegel, \& Bailey, 1986).

More research is needed on nonabused children's sexual knowledge. Work has begun in this area (Gordon, Schroeder, \& Abrams, 1990; Phipps-Yonas, Yonas, Turner, \& Kauper, 1993). However, one of the challenges is constructing studies that include material that sexually abused children might know but that nonabused children will not.

Most guidelines for sexual abuse evaluation advise interviewers to explore for sources of sexual knowledge and behavior other than abuse and, if found, to determine any relationship between the knowledge and the abuse allegations. However, there are no data that support a conclusion that because children have sexual knowledge, they will use this information to make a false accusation of sexual abuse.

\section{Adults Experience Sexual Arousal and Gratification When They Make False Allegations of Sexual Abuse}

Gardner's views about the pedophilic nature of all of us, including professionals working in sexual abuse, and his opinion that we achieve sexual gratification every time we consider the sexual acts involved in an allegation are rather astonishing. A more prevalent assumption is that exposure to sexual abuse has a dampening effect on sexual desire. Recently, this assumption and the possibility that, for some, involvement in sexual abuse may lead to involuntary, inappropriate sexual response have been addressed by professionals working in the sexual abuse field (Bays \& Bays, 1995; Maltz, 1992). These issues are just beginning to be researched. Bays and Bays (1995) are involved in two studies; the first is a survey of 142 participants in a national conference of professionals working in child maltreatment, and the second is of participants attending a conference on working with sex offenders (J. Bays, 1995).

Preliminary data are available from the first study (Bays \& Bays, 1995). About a fourth of respondents were male. On average, they were 40 years of age with a mean of 8 years of work in the sexual violence field. Although on average these professionals report moderate satisfaction with their sex lives, $21 \%$ report sexual problems that would cause them to refer a client to a professional. The researchers asked respondents about a range of possible effects of working in the field of sexual abuse, for example, intrusive thoughts about sexual violence. With regard to most of these, the 
study participants report no change because of their work. However, there is a tendency for respondents to report increases in intrusive, unwanted sexual imagery; an increased fear of rape; an increased sensitivity to sexual violence; and a decrease in the use of erotica and sexual devices. Women are more likely than men to report that working in this field has a negative effect on their sexuality. Therefore, findings so far provide no support for Gardner's (1991) assertion that sexual gratification is associated with eliciting and hearing descriptions of sexual abuse.

\section{THE PARENTAL ALIENATION SYNDROME'S UTILITY AS A SYNDROME}

In this section, there will be a discussion of definitions of syndromes and their relationship to the parental alienation syndrome and the utility of the parental alienation syndrome.

\section{What Sort of a Syndrome Is the \\ Parental Alienation Syndrome?}

A syndrome is defined in the Diagnostic and Statistical Manual of Mental Disorders (American Psychiatric Association, 1994) as a "group of symptoms that occur together and that constitute a recognizable condition." Myers (1993) notes that there is a difference between a disease, whose cause is quite likely to be known (e.g., a virus), and a syndrome, whose etiology is less certain but assumed to be present when a group of symptoms are found. Moreover, he states that some syndromes are diagnostic and others are nondiagnostic.

A syndrome is diagnostic when the symptoms relate directly to the pathological condition. Myers (1993) cites as an example the battered child syndrome, whose symptoms consist of multiple nonaccidental injuries at various stages of healing. The presence of these injuries indicates very likely that the child has been battered. He uses the term nondiagnostic syndrome to refer to syndromes whose symptoms are not directly related to the relevant diagnoses, citing as an example the child sexual abuse accommodation syndrome. Its symptoms do not tell the professional whether the child has been sexually abused. They only explain the child's symptoms, if the child has been sexually abused. The parental alienation syndrome is a nondiagnostic syndrome. It only explains the behavior of the child and the mother, if the child has not been sexually abused.

\section{The Utility of the Parental Alienation Syndrome for Mental Health Professionals and the Courts}

Because the parental alienation syndrome is a nondiagnostic syndrome, it is only useful for mental health professionals in explaining the symptom presentation if they know from other information that an abuse allegation is a deliberately made, false accusation. The syndrome cannot be used to decide whether the child has been sexually abused. As a consequence, it is of little probative value to courts making decisions about the presence or absence of sexual abuse.

Researchers and clinicians (e.g., Berliner, 1988; Faller, 1994; Jones \& McGraw, 1987; Jones \& Seig, 1988) studying false allegations have pointed out that it is extremely difficult to be certain that sexual abuse did not happen. The only way to be absolutely sure is when there has been no opportunity for the sexual contact. Unfortunately, with incest, in both intact and divorced families, adults have many opportunities for unobserved access to children. This is especially the case in divorce, in that both custodial or noncustodial parents may spend significant periods of time alone with their children.

An additional problem with the parental alienation syndrome is that virtually every symptom described by Gardner as evidence of its presence, and consequent false charges against the accused parent, is open to opposing interpretations. For example, the child's affinity for one parent and dislike of the other could have a range of causes. The child may prefer the parent who does not mistreat him or her and feel hostility toward the parent who does. The child may feel abandoned by the noncustodial parent and fear abandonment by the other parent. These feelings can result in anger toward the former and a strong cathexis to the latter.

Similarly, the mother's behavior described by Gardner as vindictive may be based on actual sexual or other abuse and therefore be better described as protective. Alternatively, she may genuinely believe that the accused parent abused the child when he did not. Then, her behavior is misguided but not vindictive.

Moreover, parental alienation syndrome lacks parsimony. Elaborated explanations and complex dynamics are proposed for the child's and the accuser's 
behavior, including a range of defense mechanisms, sexual perversity, and wickedness. Arguably, more parsimonious and likely explanations are that there is substance to the complaints of the child and the mother or that they are mistaken but not perverse, evil, and crazy.

Because of the possibility of multiple interpretations of a given symptom or series of symptoms, the parental alienation syndrome is very vulnerable to problems of interrater reliability. One expert's indicator of a false allegation may be another's indicator of a true one.

In addition, clinically, the parental alienation syndrome is not enlightening because it does not take into account the variability and range of behaviors and reactions of child, mother, and father in true and false allegations of child abuse. For example, it does not accommodate the spectrum of children's responses to an abusive parent, which may include hatred, affection, or ambivalence. Moreover, it does not acknowledge that the same child may express quite different emotions toward an abusive parent at various points in time and in various circumstances. Children may also have a range of reactions to an accused but nonabusive parent. Mothers can have a spectrum of responses to an allegation of abuse, from disbelief to belief, regardless of its veracity. The extent to which she protects the child from possible future abuse may also vary, as may her feelings about the alleged offender, regardless of the truth of the allegations. For instance, a mother may believe that her child is being maltreated but may fail to protect the child because she fears the consequences of reacting protectively.

In True and False Accusations of Child Sex Abuse, Gardner (1992c) declares that there is no such thing as a "child sex abuse syndrome" because children who have been sexually abused exhibit such a wide variety of symptoms (p. 93). Comparable criticisms regarding the usefulness of the parental alienation syndrome can also be made.

\section{CONCLUSION}

As stated in the introduction, it is important to consider and critically examine alternative explanations when children are said to have been sexually abused, including theories such as the parental alienation syndrome. Nevertheless, because the parental alienation syndrome does not directly address the ultimate issue, whether or not the child has been sexually abused, it is of little use in deciding this issue. Its only possible utility may be in understanding the behavior of the child and mother in some cases in which the allegation of mistreatment by the father is determined by other means to be false.

A fundamental flaw in the syndrome, as described by Gardner (1992a, 1992c), is that it fails to take into account alternative explanations for the child's and mother's behavior, including the veracity of the allegation or that the mother has made an honest mistake. Even in false cases, it does not take into account the full range of motivations and behaviors of children, mothers, and fathers.

No data are provided by Gardner to support the existence of the syndrome and its proposed dynamics. In fact, the research and clinical writing of other professionals leads to a conclusion that some of its tenets are wrong and that other tenets represent a minority view.

\section{APPENDIX \\ Factors in the Sexual Abuse \\ Legitimacy Scale (Gardner, 1992c)}

Factors in the Sexual Abuse Legitimacy Scale (SALS) are marked as follows: Those indicating the allegation is true are marked $\mathrm{T}$, and those indicating the allegation is false are marked $\mathrm{F}$. There are also clarifications in parentheses for factors whose meanings are obscure.

Gardner usually interviews the mother, the child, and the father, in various combinations, to gather information about these factors. He also asks to interview others, for example, relatives, friends, and therapists. Through this process, he says he collects confirming and disconfirming data and rates each factor. Note that factors vary considerably in their relevance to allegations of sexual abuse and in the degree of subjective judgment that they require. Some are quite subjective, for example, No. 14 for children, the litany. Others are more objective, for example, No. 27, school attendance and performance.

The absence of findings leads to an $\mathrm{F}$ rating. For example, if a 6-year-old has no history of running away, this is rated as disconfirming of a true allegation. If the child does not feel guilty over participation in the abuse, this is supportive of a false allegation. Similarly, if the father reports no child pornography and has no history of substance abuse, these findings are recorded as disconfirming of the abuse accusation.

\section{Indicators of the falsely accusing parent [usually a mother]}

Indicators from earlier life

1. Childhood history of having been sexually abused herself-T

2. History of poor impulse control-F

3. Passivity and/or inadequacy-T

4. Social isolation-T 


\section{APPENDIX Continued}

Indicators from events preceding the evaluation

5. Exposure of the child to sex-abuse "educational materials"-F

6. Moralism-F

7. The utilization of exclusionary maneuvers-F

8. The presence of a child custody dispute and/or litigation-F

9. The presence of the Parental Alienation Syndrome-F

10. Direct programming of the child in the sex abuse realm-F

11. Initial denial and/or downplay of the abuse- $T$

12. Failure to notify the father before reporting the alleged abuse to outside authorities- $F$

13. Enlistment of the services of a "hired gun" attorney or mental health professional-F

14. History of attempts to destroy, humiliate, or wreak vengeance on the accused-F

15. Attitude toward medical findings related to the sex abuse-F [i.e., she gives weight to minor findings]

16. Failure to appreciate the psychological trauma to the child of repeated interrogations-F

17. The acquisition of a coterie of supporters and enablers-F

18. Deep commitment to the opinions of "experts"-F [i.e., experts Gardner disagrees with]

Indicators obtained during the course of the evaluation

19. Shame over the revelation of the abuse-T

20. Attitude toward taking a lie detector test-F [i.e., reluctance to take one]

21. Appreciation of the importance of maintenance of the child's relationship with the accused-T

22. The use of the code-term "the truth" to refer to the sex-abuse scenario-F

23. Hysterical and/or exhibitionistic personality-F

24. Paranoia-F

25. Enthusiastic commitment to the data collection process-F

26. Corroboration of the child's sex-abuse description in joint interview (s) $-\mathrm{F}$

27. Cooperation during the course of the evaluation-T [i.e., Gardner's evaluation]

28. Belief in the preposterous-F

29. Expansion of the sex-abuse danger to the extended family of the accused-F

30. Duplicity in aspects of the evaluation not directly related to the sex-abuse accusation-F

\section{The differentiating criteria in the child}

1. Degree of hesitancy regarding divulgence of the sexual abuse-T [i.e., hesitant children have been abused]
2. Degree of fear of retaliation by the accused-T [i.e., fearful children have been abused]

3. Degree of guilt over the consequences of the divulgence to the accused-T [i.e., children who feel guilty have been abused]

4. Degree of guilt over participation in the sexual acts-T [i.e., children who feel guilty have been abused]

5. Degree of specificity of the details of the sexual abuse-T [i.e., children who give details have been abused]

6. Credibility of the description-T

7. Variations in the description-T

8. Advanced sexual knowledge for age- $-\mathrm{T}$

9. Sexual excitation-T

10. Attitude toward one's genitals- $T$ [i.e., children with negative feelings toward genitals have been abused]

11. Desensitization play-T

12. Threats and bribes-T

13. Custody/visitation disputes-F

14. The litany-F

15. The borrowed scenario- $F$

16. Depression-T

17. Withdrawal-T

18. Pathological compliance-T

19. Psychosomatic disorders-T

20. Regressive behavior-T

21. Sense of betrayal-T

22. Sleep disturbances-T

23. Chronicity of abuse-T

24. Seductive behavior (primarily girls) $-\mathrm{T}$

25. Pseudomaturity (primarily girls) $-\mathrm{T}$

26. Antisocial acting out-T

27. School attendance and performance-T [i.e., poor attendance and performance]

28. Fears, tension, and anxiety-T

29. Running away from home- $\mathrm{T}$

30. Severe psychopathology-T

\section{Indicators of pedophilia in the male}

1. History of family influence conducive to the development of significant psychopathology- $\mathrm{T}$

2. Long-standing history of emotional deprivation-T

3. Intellectual impairment-T

4. History of childhood sex abuse-T

5. Long-standing history of very strong sexual urges$\mathrm{T}$

6. Impulsivity-T

7. Feelings of inadequacy and compensatory narcissism- $T$

8. Coercive-dominating behavior-T

9. Passivity and impaired self-assertion-T

10. History of substance abuse- $T$

11. Poor judgment-T

12. Impaired sexual interest in age-appropriate women- $\mathrm{T}$ 


\section{APPENDIX Continued}

13. Presence of other sexual deviations-T

14. Psychosis-T

15. Immaturity and/or regression- $T$

16. Large collection of child pornographic materials-T

17. Career choice that brings him in contact with children-T

18. Recent rejection by a peer or dysfunctional heterosexual relationship-T

19. Unconvincing denial-T

20. Use of rationalizations and cognitive distortions that justify pedophilia - T

21. Resistance to taking a lie detector test-T

22. Lack of cooperation in the evaluative examination- $\mathrm{T}$

23. Duplicity unrelated to sex abuse denial and psychopathic tendencies- $\mathrm{T}$

24. Excessively moralistic attitudes-T

\section{NOTES}

1. Although, according to Gardner (1992a), $10 \%$ of accusing parents are fathers, his work focuses on accusing mothers. Therefore, throughout this article, the accusing parent is referred to as "her" or as "the mother."

2. However, Gardner includes advanced sexual knowledge and seductive behavior in the Sexual Abuse Legitimacy Scale (SALS) and in his list of factors in Protocols for the Sex-Abuse Evaluation as indicating the child is telling the truth about sexual abuse. Thus, he is inconsistent in his views about children's sexual knowledge and behavior.

3. Gardner's fees can be as high as $\$ 400$ per hour.

4. The 84 factors in the SALS appear in the appendix.

5 . As Note 2 indicates, these positions are not consistent with his inclusion of sexual knowledge and sexualized behavior as children's indicators of the likelihood of sexual abuse.

\section{REFERENCES}

American Psychiatric Association. (1994). Diagnostic and statistical manual of mental disorders (4th ed.). Washington, DC: Author.

August, R., \& Foreman, B. (1989). A comparison of sexually abused and nonsexually abused children's behavioral responses to anatomically correct dolls. Child Psychiatry and Human Development. 20(1), 39-47.

Bays, J. (1995, January). Does working with sexual violence affect your sexuality? Paper presented at the National Conference on Responding to Child Maltreatment, San Diego, CA.

Bays, L., \& Bays, J. (1995). Does working with sexual violence affect your sexuality? Unpublished preliminary findings.

Benedek, E., \& Schetky, D. (1985). Allegations of sexual abuse in child custody cases. In E. Benedek \& D. Schetky (Eds.), Emerging issues in child psychiatry and the law (pp. 145-156). New York: Brunner/Mazel.

Benedek, E., \& Schetky, D. (1987). Clinical experience: Problems in validating allegations of sexual abuse: Part 1 . Factors affecting the perception and recall of events. Journal of the American Academy of Child and Adolescent Psychiatry, 26(6), 912-915.

Berliner, L. (1988). Deciding whether a child has been sexually abused. In E. Nicholson \& J. Bulkley (Eds.), Child sexual abuse allegations in divorce and custody disputes. Washington, DC: American Bar Association.

Berliner, L., \& Conte, J. (1993). Sexual abuse evaluations: Conceptual and empirical obstacles. Child Abuse and Neglect, 16(1), 111-125.
Boat, B., \& Everson, M. (1994). Exploration of anatomical dolls by nonreferred preschool-aged children: Comparisons by age, gender, race, and socioeconomic status. Child Abuse and Neglect, 18(2), 139-153.

Bogolub, E. (1997). Divorce. R. Edwards (Ed.) Encyclopedia \& Social Work (19th ed., suppl) Silver Springs, MD: National Association of Social Workers.

Cohen, D. (1991). Anatomical doll play of preschoolers referred for sexual abuse and those not referred. Child Abuse and Neglect, 15(4), 455-66.

Conte, J., Sorenson, E., Fogarty, L., \& Dalla Rosa, J. (1991). Evaluating children's reports of sexual abuse: Results from a survey of professionals. American Joumal of Orthopsychiatry, 61(3), 428-437.

Corwin, D. (1988). Early diagnosis of child sexual abuse: Diminishing the lasting effects. In G. Wyatt \& G. Powell (Eds.), The lasting effects of child sexual abuse. Newbury Park, CA: Sage.

De Young, M. (1986). A conceptual model for judging the truthfulness of a young child's allegation of sexual abuse. American Journal of Orthopsychiatry, 56(4), 550-559.

Everson, M., \& Boat, B. (1990). Sexualized doll play among young children: Implications for the use of anatomical dolls in sexual abuse evaluations. Journal of the American Academy of Child and Adolescent Psychiatry, 29(5), 736-742.

Faller, K. C. (1988a). Child sexual abuse: An interdisciplinary manual for diagnosis, case management, and treatment. New York: Columbia University Press.

Faller, K. C. (1988b). Criteria for judging the credibility of children's statements about their sexual abuse. Child Welfare, 7(5), $389-401$.

Faller, K. C. (1990). Understanding child sexual maltreatment. Newbury Park, CA.: Sage.

Faller, K. C. (1991). Possible explanations for child sexual abuse allegations in divorce. American Journal of Orthopsychiatry, 61(1), 86-91.

Faller, K. C. (1994). Child sexual abuse allegations: How to decide when they are true. Violence Update, 4(6), 1-2, 4, 8, 10-11.

Faller, K. C., \& DeVoe, E. (1995). Allegations of sexual abuse in divorce. Journal of Child Sexual Abuse, 4(4), 1-25.

Faller, K. C., Olafson, E., \& Corwin, D. (1993). Research on false allegations of sexual abuse in divorce. The APSAC Advisor, 6(3), 1, 7-10.

Friedrich, W. (1990). Psychotherapy with sexually abused children and their families. New York: Norton.

Friedrich, W. (1993). Sexual victimization and sexual behavior in children: A review of recent literature. Child Abuse and Neglect, $17(1), 59-66$.

Friedrich, W. (1994, January). Standardized measures for assessing child sexual abuse. Workshop presented at the National Conference on Responding to Child Maltreatment, San Diego, CA.

Friedrich, W., Berliner, L., Butler, J., Cohen, J., Damon, L., \& Shafram, C. (1996a). Child sexual behavior: An update with the CSBI-3. APSAC Advisor, 9(4), 13-14.

Friedrich, W., Berliner, L., Butler, J., Cohen, J., Damon, L., \& Shafram, C. (1996b, July). Normative sexual behaviors: CSBI-3. Paper presented at Trauma and Memory: An International Research Conference. Durham, NH.

Friedrich, W., Grambsch, P., Broughton, D., Kuiper, J., \& Beilke, R. (1991). Normative sexual behavior in children. Pediatrics, 88(3), 256-464.

Gardner, R. (1987). The parental alienation syndrome and the differentiation between fabricated and genuine child sexual abuse. Cresskill, NJ: Creative Therapeutics.

Gardner, R. (1989). Differentiating between bona fide and fabricated allegations of sexual abuse of children. Journal of the American Academy of Matrimonial Lawyers, 5, 1-25.

Gardner, R. (1991). Sex abuse hysteria: The Salem witch trials revisited. Cresskill, NJ: Creative Therapeutics.

Gardner, R. (1992a). The parental alienation syndrome. Cresskill, NJ: Creative Therapeutics.

Gardner, R. (1992b). Qualifications of Richard A. Gardner, M.D. for providing court testimony. Unpublished document. 
Gardner, R. (1992c). True and false allegations of child sex abuse. Cresskill, NJ: Creative Therapeutics.

Gardner, R. (1995). Protocols for sex-abuse evaluation. Cresskill, NJ: Creative Therapeutics.

Gardner, R. (1996). Books, tapes, and psychotherapeutic instruments for psychotherapists, counselors, teachers, lawyers, parents, and children. Cresskill, NJ: Creative Therapeutics.

Gordon, B., Schroeder, C., \& Abrams, J. (1990). Children's knowledge of sexuality: A comparison of sexually abused and nonabused children. American Journal of Orthopsychiatry, 60, 250-257.

Green, A. (1986). True and false allegations of sexual abuse in child custody disputes. Journal of the American Academy of Child Psychiatry, 25(4), 449-456.

Hazzard, A., Webb, C., Kleemeier, C., Angert, L., \& Pohl, J. (1991). Child sexual abuse prevention: Evaluation and one-year followup. Child Abuse and Neglect, 15, 123-138.

Heiman, M. (1992). Annotation: Putting the puzzle together: Validating allegations of child sexual abuse. Journal of Child Psychology and Psychiatry, 33(2), 311-329.

Herman, J. (1979). Father-daughter incest. Cambridge, MA: Harvard University Press.

Jacobson, D. (1987). Divorce and separation. In A. Minahan (Ed.), Encyclopedia of social work (19th ed.). Silver Spring, MD: National Association of Social Workers.

Jampole, L., \& Webber, M. (1987). An assessment of the behavior of sexually abuse and non-sexually abused children with anatomically correct dolls. Child Abuse and Neglect, 11, 187-192.

Jones, D., \& McGraw, M. (1987). Reliable and fictitious accounts of sexual abuse to children. Journal of Interpersonal Violence, 2(1), $27-45$

Jones, D., \& Seig, A. (1988). Child sexual abuse allegations in custody or visitation cases: A report of 20 cases. In B. Nicholson \& J. Bulkley (Eds.), Sexual abuse allegations in custody and visitation cases. Washington, DC: American Bar Association.

Kaplan, S., \& Kaplan, S. (1981). The child's accusation of sexual abuse during a divorce and custody struggle. Hillside Journal of Clinical Psychiatry, 3(1), 81-95.

Klajner-Diamond, H., Wehrspann, W., \& Steinhauer, P. (1987). Assessing the credibility of young children's allegations of sexual abuse: Clinical issues. Canadian Journal of Psychiatry, 32(7), 610-614.

Kolko, D. (1988). Educational programs to promote awareness and prevention of child sexual victimization: A review and methodological critique. Clinical Psychology Review, 8, 195-209.

Maltz, W. (1992). Caution: Treating sexual abuse can be hazardous to your love life. Treating Abuse Today, 2(2), 20-24.

Masson, G. (1987). Assault on the Truth. New York: Doubleday.

Miller, A. (1984). Thou shalt not be aware: Society's betrayal of the child. New York: New American Library.

Morgan v. Foretich, Foretich, \& Foretich (D. Virginia 1987) (testimony of E. Benedek)

Myers, J. (1993). Expert testimony describing psychological syndromes. Pacific Law Journal, 24(3), 1449-1464.

Paradise, J., Rostain, A., \& Nathanson, M. (1988). Substantiation of sexual abuse charges when parents dispute custody or visitation. Pediatrics, 81(6), 835-839.
Phipps-Yonas, S., Yonas, A., Turner, M., \& Kauper, M. (1993). Sexuality in early childhood. University of Minnesota Center for Urban and Regional Affairs Reporter, 23(2), 1-5.

Plummer, C. (1986). Prevention in perspective. In M. Nelson \& K Clark (Eds.), The educator's guide to preventing child sexual abuse (pp. 1-5). Santa Cruz, CA: Network Publications.

Raskin, D., \& Esplin, P. (1991). Assessment of children's statements of sexual abuse. In J. Doris (Ed.), The suggestibility of children's recollections (pp. 153-164). Washington, DC: American Psychological Association.

Rosenfeld, A., Bailey, R., Siegel, B., \& Bailey, G. (1986). Determining incestuous contact between parent and child: Frequency of children touching parents' genitals in a nonclinical population. Journal of the American Academy of Child Psychiatry, 25(4), 481-484.

Rush, F. (1977). The Freudian cover-up. Chrysalis, 1, 31-45.

Schuman, D. (1986). False allegations of physical and sexual abuse. Bulletin of the American Academy of Psychiatry and the Law, 14(1), 5-21.

Sgroi, S. (1982). Handbook on clinical intervention in child sexual abuse. Lexington, MA: Lexington Books.

Sink, F. (1988). A hierarchical model for evaluation of child sexual abuse. American Journal of Orthopsychiatry, 58(1), 129-135.

Sivan, A., Schor, D., Koeppl, G., \& Noble, L. (1988) Interaction of normal children with anatomical dolls. Child Abuse and Neglect, 12, 295-304.

Thoennes, N., Pearson, J., \& Tjaden, P. (1988). Allegations of sexual abuse in custody and visitation disputes. Denver, CO: Association of Family and Conciliation Courts.

Thoennes, N., \& Tjaden, P. (1990). The extent, nature, and validity of sexual abuse allegations in custody/visitation disputes. Child Abuse and Neglect, 14, 151-163.

Ward, E. (1985). Father-daughter rape. New York: Grove.

Waterman, J., \& Lusk, R. (1993). Psychological testing in evaluation of child sexual abuse. Child Abuse and Neglect, 17, 145-159.

White, S., Strom, G., Santilli, G., \& Halpin, B. (1986). Interviewing young sexual abuse victims with anatomically correct dolls. Child Abuse and Neglect, 10, 519-529.

Wurtele, S., \& Miller-Perrin, C. (1992). Preventing child sexual abuse Lincoln: University of Nebraska Press.

Kathleen Coulborn Faller, Ph.D., A.C.S.W., D.C.S.W., is professor of social work, faculty director of the CIVITAS Child and Family Programs, and director of the Family Assessment Clinic, a multidisciplinary team, all at the University of Michigan. She is the author of Social Work With Abused and Neglected Children; Child Sexual Abuse: An Interdisciplinary Manual for Diagnosis, Case Management, and Treatment; Understanding Child Sexual Maltreatment; Child Sexual Abuse Intervention and Treatment Issues; APSAC Study Guide: Evaluating Children Suspected of Having Been Sexually Abused; and approximately 35 research and practice articles on child abuse and neglect. 